\title{
A rua é minha casa: condições de vida de pessoas em situação de rua em um município de Santa Catarina
}

Carlos Francisco Duarte Junior', Cláudia Regina Lima Duarte da Silva², Marco Aurélio Da Ros $^{3}$, Ana Claudia Boso ${ }^{4}$

\section{Resumo}

A população em situação de rua constitui um grupo de pessoas que está à margem da sociedade. Considerando que as condições sociais são determinantes do processo saúde-doença, as iniquidades sociais acabam por tornar essa população extremamente vulnerável ao adoecimento, visto que muitas de suas necessidades básicas não são contempladas. Esta pesquisa teve como objetivo conhecer histórias de vida e estratégias de sobrevivência de pessoas em situação de rua em um município de grande porte do estado de Santa Catarina, Brasil. Foi realizada uma pesquisa qualitativa em que cinco pessoas em situação de rua maiores de 18 anos participaram de uma entrevista semiestruturada. Os relatos das histórias de vida dos entrevistados foram organizados com base na técnica de análise de conteúdo de Bardin (2011) e neste artigo será discutida a categoria "Sobrevivendo nas ruas e às ruas". Os dados da pesquisa permitiram identificar que as histórias de vida das pessoas em situação de rua no município em questão são marcadas por uma sucessão de tragédias, perdas, violências, exclusão social, dificuldade de acesso aos serviços públicos e negação aos direitos humanos e, paradoxalmente, algum sentimento de pertencimento, de identidade com grupo, de facilidades para sobrevivência.

\section{Palavras-chave}

Pessoas em Situação de Rua. Pobreza. Condições de Vida.

1. Mestre em Saúde Coletiva pela Universidade Regional de Blumenau, Santa Catarina, Brasil; professor da Universidade do Vale do Itajaí, Santa Catarina, Brasil. E-mail: cfdjunior@hotmail.com.

2. Doutora em Enfermagem pela Universidade Federal de Santa Catarina, Brasil; professora da Universidade Regional de Blumenau, Santa Catarina, Brasil. E-mail: claudiaduarte1108@gmail.com.

3. Pós-doutor em Educação Médica pela Universidade de Bolonha, Itália; professor da Universidade do Vale do Itajaí, Santa Catarina, Brasil. E-mail: ros@univali.br.

4. Especialista em Medicina de Família e Comunidade pela Universidade do Vale do Itajaí, Santa Catarina, Brasil. E-mail: aana-claudia@hotmail.com. 


\title{
The street is my home: living conditions of homeless people in a city of Santa
} Catarina, Brazil

Carlos Francisco Duarte Junior*, Cláudia Regina Lima Duarte da Silva**, Marco Aurélio Da Ros $^{* * *}$, Ana Claudia Boso****

\begin{abstract}
Homeless people are a group of people who are on the margins of society. Considering that social conditions are determinants of the health-disease process, social inequities end up making this population extremely vulnerable to illness, since many of their basic needs are not contemplated. This research aimed to get to know life histories and strategies of survival of homeless people in a large city of the state of Santa Catarina, Brazil. A qualitative research was carried out in which five homeless persons older than 18 years old participated in a semi-structured interview. The interviewees' life histories reports were organized based on Bardin's (2011) content analysis technique and in this article the category "Surviving on the streets and despite the streets" will be herein discussed. The research data made it possible to identify that the life histories of homeless people in the municipality in question are marked by a succession of tragedies, losses, violence, social exclusion, difficulty in accessing public services and denial of human rights, and, paradoxically, some feeling of belonging, of group identity, and of survival easiness.
\end{abstract}

\section{Keywords}

Homeless People. Poverty. Social Conditions.

* Master of Public Health, Regional University of Blumenau, State of Santa Catarina, Brazil; professor at the University of the Vale do Itajaí, State of Santa Catarina, Brazil. E-mail: cfdjunior@hotmail.com.

** PhD in Nursing, Federal University of Santa Catarina, Brazil; professor at the Regional University of Blumenau, State of Santa Catarina, Brazil. E-mail: claudiaduarte1108@gmail.com.

*** Post-doctorate in Medical Education, University of Bologna, Italy; professor at the University of the Vale do Itajaí, State of Santa Catarina, Brazil. E-mail: ros@univali.br.

**** Specialist in Family and Community Medicine, University of Vale do Itajaí, State of Santa Catarina, Brazil. E-mail: aana-claudia@hotmail.com. 


\section{Introdução}

A iniquidade social resultante do modo de produção capitalista produz diferentes grupos populacionais, mais ou menos marginalizados, estando as pessoas em situação de rua naquele que tem a maioria de seus direitos negados, tornando-seinválidospela conjunturaeconômica e social atual, originando um fenômeno complexo que não pode ser caracterizado apenas pela falta de moradia (CASTEL, 1997).

A Política Nacional para a População em Situação de Rua (PSR) foi instituída pelo Decreto Presidencial $\mathrm{n}$ - 7.053, de 23 de dezembro de 2009, e considera a população em situação de rua como:

o grupo populacional heterogêneo que possui em comum a pobreza extrema, os vínculos familiares interrompidos ou fragilizados e a inexistência de moradia convencional regular, e que utiliza os logradouros públicos e as áreas degradadas como espaço de moradia e de sustento, de forma temporária ou permanente, bem como as unidades de acolhimento para pernoite temporário ou como moradia provisória. (BRASIL, 2009).

Entre os objetivos dessa política está o de assegurar o acesso amplo, simplificado e seguro aos serviços e programas que integram as políticas públicas de saúde, educação, previdência, assistência social, moradia, segurança, cultura, esporte, lazer, trabalho e renda (BRASIL, 2009). Um de seus principais desafios está em propor estratégias de enfrentamento às questões de saúde, pois na organização dos serviços de saúde, a PSR ainda não se tem constituído como uma questão de intervenção mais articulada no interior de suas práticas, e tomar esta população como uma questão social para a área da saúde é pertinente, pois suas condições de vida determinam processos de saúde-doença-cuidado muito diferenciados, demandando novos arranjos tecnoassistenciais e políticas públicas (BARATA et al., 2015; CARNEIRO JUNIOR et al., 1998).

Embora a Política Nacional esteja em vigor há quase uma década, ainda predominam os problemas de acesso, estigma, preconceito, despreparo profissional, desarticulação entre os setores, cuidado uniprofissional e uma atenção à saúde voltada para ações assistencialistas e medicalizantes. O desenho tradicional das políticas de proteção social ainda é marcado pela descontinuidade dos projetos e programas, pelas ações pontuais de distribuição de alimentação, passagens de ônibus, roupas, banhos e pela cultura predominante do recolhimento em albergues e encaminhamentos para comunidades terapêuticas, com uma estreita porta de entrada nas instituições, mas sem a utópica porta de saída que possa garantir uma reinserção social (PAIVA, 2016).

Apesar das dificuldades encontradas para o levantamento demográfico, é notório o aumento do número de pessoas em situação de rua, principalmente nos grandes centros urbanos. Sendo uma população pouco estudada (e compreendida), as políticas públicas habitualmente não vão ao encontro de suas necessidades reais, gerando, em alguns casos, práticas higienistas e pouco resolutivas, muitas vezes respondendo ao senso comum um tanto quanto contraditório, no qual a preocupação demonstrada com as pessoas em situação de rua confunde-se com determinada necessidade de manter as ruas "limpas e seguras". Numa sociedade global, na qual a quantificação tem, sem qualquer dúvida, o seu valor, a construção narrativa dos seres humanos, ou determinados grupos de seres humanos, em determinado momento histórico ou temporal, acerca dos fenômenos sociais, irá ter, provavelmente, cada vez maior relevância (ARAÚJO et al., 2016). Assim, é necessário considerar os indivíduos como atores sociais, 
definidos ao mesmo tempo por esse espaço social no qual se inserem e pela consciência de agir sobre esse espaço (GERHARDT, 2006; BRASIL, 2012).

$O$ interesse pela pesquisa surge da experiência dos pesquisadores em atuar como profissionais desaúde, muitas vezestendo delidar com situações de vulnerabilidade das pessoas em situação de rua, sem uma rede de apoio social. Além disso, algumas fragilidades da Rede de Atenção Psicossocial (RAPS) no município estudado dificultam projetos terapêuticos que rompam com o modelo biomédico tradicional e que atendam às suas necessidades. Somandose a isso, comumente nos deparamos com campanhas de "enfrentamento" à PSR baseadas em práticas não humanizadas que frustram aqueles que enxergam em suas profissões uma maneira de lutar por justiça social.

Neste sentido, a presente pesquisa teve por objetivo conhecer histórias de vida e estratégias de sobrevivência de pessoas em situação de rua em um município de grande porte do estado de Santa Catarina, a fim de subsidiar uma proposta de educação em saúde sob a perspectiva da educação popular.

Partindo do pressuposto que o processo saúde-doença resulta de uma série de fatores determinantes e condicionantes, como acesso à educação, lazer, cultura, moradia, vínculos familiares, fica claro, especialmente nesse recorte populacional, que o modelo biomédico de atenção à saúde acaba não sendo suficiente para produzir o cuidado e melhores condições de vida, tampouco para a prática de educação em saúde. Dessa forma, entender a lógica da PSR facilitaria a construção de planos conjuntos, tanto de educação em saúde (já referenciada), como de atenção às suas necessidades, estando justamente aí o fulcro dessa pesquisa.

\section{Metodologia}

Trata-se de um estudo qualitativo, e sua escolha se justifica por este responder a questões muito particulares, com um nível de realidade que não pode ou não deveria ser quantificado (MINAYO, 2014).

A pesquisa foi realizada nas ruas e praças públicas de um município de grande porte do estado de Santa Catarina, Brasil. Os sujeitos desse estudo foram pessoas maiores de 18 anos que se encontravam em situação de rua nesse município, que desejaram e tiveram disponibilidade para participar da pesquisa, e que demonstraram lucidez e coerência na resposta ao seu perfil antes da entrevista. O que caracterizou a pessoa em situação de rua foi a resposta ao item do perfil "Onde costuma dormir?", sendo incluídas as pessoas que responderam que costumam dormir na "rua", entendendo "rua" no seu sentido amplo, incluindo todos os possíveis locais relativamente protegidos do frio e da exposição à violência e que podem servir como abrigo.

O estudo foi feito em etapa única por meio de entrevista semiestruturada que oportunizou as pessoas falarem sobre suas histórias de vida. O pesquisador foi até uma praça pública em região central do município no dia 18 de janeiro de 2018, local onde normalmente são encontradas pessoas em situação de rua, solicitou autorização e abordou de maneira informal, respeitosa e, de forma horizontalizada, uma pessoa que se encontrava nessa condição, convidando-a a participar da pesquisa. Foram explicados os motivos, objetivos e o método da pesquisa, bem como lido o Termo de Consentimento Livre e Esclarecido (TCLE), em linguagem clara e acessível. Ao término da primeira entrevista, o entrevistado foi convidado a indicar o próximo 
conforme a técnica da "bola de neve". Essa técnica é uma forma de amostra não probabilística utilizada em pesquisas sociais em que os participantes iniciais de um estudo indicam novos participantes que, por sua vez, indicam outros e assim sucessivamente, até que seja alcançado o objetivo proposto, ou seja, a saturação de dados, que é a suspensão da inclusão de entrevistados quando as informações obtidas passam a apresentar, na avaliação do pesquisador, certa redundância ou repetição, não sendo considerado relevante persistir na coleta de dados (ALBUQUERQUE, 2009; FONTANELLA et al., 2011). As entrevistas foram gravadas e posteriormente transcritas.

Os entrevistados foram convidados a falar sobre suas histórias de vida e os dados foram organizados com a técnica de análise de conteúdo temático-categorial de Bardin (2011), percorrendo as três fases básicas: a pré-análise; a exploração do material; e o tratamento dos resultados, inferência e interpretação.

Com base na análise das entrevistas, foram elencadas as seguintes categorias: "Sobrevivendo nas ruas e às ruas", "Os (des) caminhos que levam às ruas", "Os olhos que não veem, mas condenam", "Drogas como possibilidade de vida", "O que não mata, fortalece?" e "Das redes às grades". Este artigo trata da categoria "Sobrevivendo nas ruas e às ruas".

A coleta dos dados se deu somente após aprovação do projeto pelo Comitê de Ética da instituição na qual o trabalho foi realizado. Esta pesquisa seguiu os preceitos éticos exigidos pela Resolução $\mathrm{n}$ 은 466/2012 do Conselho Nacional de Saúde.

\section{Resultados e Discussão}

O trabalho de campo possibilitou elencar algumas categorias temáticas, dentre as quais a destacada neste artigo, que trata das condições de vida das pessoas entrevistadas. Os relatos das histórias de vida tiveram que ser recortados para garantir a especificidade dessa categoria. Além disso, proporcionouaobtençãodascaracterísticas sociais, demográficas e econômicas, conforme se reporta no quadro abaixo (Quadro 1). 
Quadro 1 - Caracterização sociodemográfica e econômica das pessoas em situação de rua entrevistadas

\begin{tabular}{|c|c|c|c|c|c|}
\hline & E1 & E2 & E3 & E4 & E5 \\
\hline Idade & 34 anos & 19 anos & 53 anos & 30 anos & 44 anos \\
\hline Gênero & Masculino & Masculino & Masculino & Masculino & Feminino \\
\hline Escolaridade & $\begin{array}{l}\text { Fundamental } \\
\text { incompleto }\end{array}$ & $\begin{array}{l}\text { Fundamental } \\
\text { incompleto }\end{array}$ & $\begin{array}{l}\text { Fundamental } \\
\text { incompleto }\end{array}$ & $\begin{array}{l}\text { Fundamental } \\
\text { incompleto }\end{array}$ & $\begin{array}{l}\text { Fundamental } \\
\text { incompleto }\end{array}$ \\
\hline Profissão & $\begin{array}{l}\text { Lavador de } \\
\text { carros }\end{array}$ & Artista de rua & Pintor & Pintor & Camareira \\
\hline Ocupação & Não tem & Artista de rua & $\begin{array}{l}\text { Catador de } \\
\text { reciclagem }\end{array}$ & Biscate & Não tem \\
\hline Renda & Não tem & 50 reais/dia & Indeterminada & 10 reais/dia & Não tem \\
\hline Benefício & Não tem & Não tem & Não tem & Não tem & Não tem \\
\hline Naturalidade & Osasco/SP & Porto Alegre/RS & Joinville/SC & $\begin{array}{l}\text { Florianópolis/ } \\
\text { SC }\end{array}$ & Mucuri/BA \\
\hline Origem & São Paulo/SP & $\begin{array}{l}\text { Balneário } \\
\text { Camboriú/SC }\end{array}$ & Ilhota/SC & Itajaí/SC & $\begin{array}{l}\text { Balneário } \\
\text { Piçarras/SC }\end{array}$ \\
\hline Tempo na rua & 10 anos & 1 ano & 5 anos & 5 anos & 2 anos \\
\hline $\begin{array}{l}\text { Tempo no } \\
\text { município }\end{array}$ & 2 semanas & 1 semana & $\begin{array}{l}1 \text { dia } \\
\text { (vai e volta) }\end{array}$ & 9 anos & 2 anos \\
\hline $\begin{array}{l}\text { Local onde } \\
\text { dorme }\end{array}$ & $\begin{array}{l}\text { Marquise/ } \\
\text { Praça }\end{array}$ & $\begin{array}{l}\text { Mercado } \\
\text { público }\end{array}$ & Marquise & Marquise & Marquise \\
\hline $\begin{array}{l}\text { Local onde se } \\
\text { alimenta }\end{array}$ & $\begin{array}{l}\text { Lixo/ } \\
\text { Restaurante }\end{array}$ & Na rua & $\begin{array}{l}\text { Faz comida, } \\
\text { ganha }\end{array}$ & Ganha marmita & $\begin{array}{l}\text { Restaurante/ } \\
\text { Pastor }\end{array}$ \\
\hline Higiene & Rio & $\begin{array}{l}\text { Banheiros } \\
\text { públicos/lojas }\end{array}$ & $\begin{array}{l}\text { Posto de } \\
\text { gasolina/praia }\end{array}$ & $\begin{array}{l}\text { Banheiro } \\
\text { público/ } \\
\text { Mercado }\end{array}$ & $\begin{array}{l}\text { Casa de } \\
\text { Apoio/ } \\
\text { banheiro } \\
\text { público }\end{array}$ \\
\hline Vínculos & Irmão & $\begin{array}{l}\text { Pai/mãe (redes } \\
\text { sociais) }\end{array}$ & Ninguém & Pai e mãe & $\begin{array}{l}\text { Filho } \\
\text { (junto na rua) }\end{array}$ \\
\hline
\end{tabular}

Fonte: O autor (2018). 
Confrontando os dados com a Pesquisa Nacional Sobre a População em Situação de Rua de 2007/2008 (BRASIL, 2008), nota-se que as características sociodemográficas e econômicas são semelhantes, e algumas serão discutidas abaixo.

$\mathrm{Na}$ Pesquisa Nacional, o sexo masculino predominava (82\%) entre as pessoas em situação de rua, equivalente ao observado neste trabalho. Sabendo-se que o número de mulheres no Brasil é maior que o de homens, chama atenção o fato de que a população em situação de rua é basicamente masculina.

Em Tiene, citada por Costa (2005) é feita uma análise de gênero, identificando que para as mulheres, habitualmente imaginadas num ambiente doméstico e protetor, o contraste em estar nas ruas salta aos olhos. Para os homens, estar na rua é também frequentar o espaço público, para o qual foram acostumados a conviver e buscar a sobrevivência. As mulheres em situação de rua sempre são minoria e, aquelas que lá estão, têm trajetórias e adotam estratégias diferenciadas de seus companheiros de rua.

A população identificada pela Pesquisa Nacional, em geral, era jovem, sendo que mais da metade (53\%) se situava na faixa etária entre 25 e 44 anos, à semelhança do que pode ser observado no quadro acima. No que diz respeito à formação escolar, a maior parte $(63,5 \%)$ não havia concluído o ensino fundamental, sendo que no presente estudo a totalidade dos entrevistados não possuía ensino fundamental completo.

A PSR, na Pesquisa Nacional, era composta em grande parte por trabalhadores: $70,9 \%$ que exerciam alguma atividade remunerada. Dos entrevistados neste trabalho, a totalidade informa possuir profissão, mesmo que não a exerça, explicitando a profissão como uma parte importante da identidade social do indivíduo, ou seja, começa-se a perceber que a PSR busca de alguma maneira garantir uma identidade social.
Entre as ocupações mais comuns das pessoas em situação de rua estão a coleta de material reciclável, a guarda de carros, o serviço doméstico e a construção civil. Essas profissões, como não são exercidas com regularidade, muitas vezes não garantem o sustento. Os benefícios sociais acabam sendo a única alternativa de sobrevivência em muitas situações (COSTA, 2005). Os entrevistados não recebiam nenhum tipo de benefício social.

Os principais locais utilizados pelas pessoas em situação de rua para tomar banho e fazer suas necessidades fisiológicas, tanto na Pesquisa Nacional quanto neste estudo, eram a rua e os albergues/abrigos.

Em relação aos vínculos familiares, na Pesquisa Nacional a maior parte dos entrevistados havia rompido o vínculo familiar, diferente do encontrado neste estudo, em que apenas um dos entrevistados relatou essa condição.

Costa (2005, p. 3) define a PSR como parte de um "grupo populacional heterogêneo, composto por pessoas com diferentes realidades, mas que têm em comum a condição de pobreza absoluta e a falta de pertencimento à sociedade formal". São homens, mulheres, jovens, famílias inteiras, grupos, que têm em sua trajetória a referência de ter realizado alguma atividade laboral, que foi importante na constituição de suas identidades sociais. Com o tempo, algum infortúnio atingiu suas vidas, seja a perda do emprego, seja o rompimento de algum laço afetivo, fazendo com que aos poucos fossem perdendo a perspectiva de projeto de vida, passando a utilizar o espaço da rua como sobrevivência e moradia (COSTA, 2005).

Pode-se perceber que boa parte das características sociodemográficas e econômicas da população entrevistada figuram entre as destacadas nas referências citadas anteriormente. Convém salientar que a Pesquisa Nacional foi realizada há mais de uma década e, sendo assim, é possível que tenhamos um grupo de pessoas em situação de rua muito 
maior e mais heterogêneo, principalmente se considerarmos o momento socioeconômico brasileiro atual, gerado em parte pela crise política instalada, em que assistimos o desmonte de programas sociais e a perda de direitos trabalhistas previamente adquiridos.

\section{Sobrevivendo nas ruas e às ruas}

Partindo do pressuposto que o processo saúde-doença é socialmente determinado, saber como a PSR existe em seu espaço e quais estratégias essa população utiliza para sobreviver se torna o primeiro passo para compreender e traçar medidas que atendam às demandas de sua complexidade.

As entrevistas revelam como as pessoas em situação de rua fazem para suprir as necessidades humanas básicas e as motivações que as levam a satisfazê-las. Para manter a existência e a sobrevivência, o ser humano necessita de alimento, água, abrigo e do atendimento a necessidades fisiológicas que constituiriam uma base para que outras necessidades fossem contempladas, como lazer, emprego, relações sociais, respeito, dignidade, autorrealização, entre outras. Conhecer como o espaço urbano se constitui é necessário para entender como o "estar em situação de rua" influencia nas condições de vida e saúde desse segmento populacional. É preciso compreender os motivos que levam os indivíduos em situação de rua a se estabelecerem nos territórios urbanos e, também, que a organização e o desenvolvimento socioespacial do território influenciam substancialmente a vida das pessoas que os utilizam para moradia e subsistência (FRAGA, 2015).

A PSR se estabelece de forma marcante nas regiões centrais das metrópoles, pois essas áreas costumam oferecer mais condições de levar suas vidas, mais chances de conseguir alimentação, oferecer algum serviço, conseguir alguma renda: grande concentração de serviços, baixa concentração de residências e alta circulação de pessoas (CARNEIRO JUNIOR; JESUS; CREVELIM, 2010).

Em relação à alimentação, o Entrevistado 1 (E1) afirmou: "Eu cato comida do lixo, aí eu venho, como aqui e, quando chega a noite, eu durmo aqui no meio, na praça, nas lojas... Então, eu vou nos restaurantes, mas é difícil o pessoal dar. Daí eu cato do lixo e como né. Tenho uma cambuquinha de por comida aí. Espero o pessoal jogar fora e como."

O Entrevistado 4 (E4): "Eu tenho que fazer a minha caminhada. Pedir pra um, pedir pra outro. Tem aqui a mulher que dá bolo pra mim. Tem a mulher ali que dá cafezinho pra mim. Ah, hoje é sexta-feira, eu pego a marmita ali ó".

Para o Entrevistado 5 (E5): "Ah, às vezes vamo no restaurante e pegamo né? Tem que esperar, 3 horas, 4 horas, que um ou outro dá pra gente. À noite é os pastores que traz pra nós. Nem todo dia. Ontem eu dormi com fome. Eu esperei, esperei, não veio marmita".

Sobre as eliminações fisiológicas, o E1 afirmou: "Pego umas beiras do rio aí que ninguém vê. Você tem que evitar fazer na sociedade né. Isso é o principal, né cara?". O Entrevistado 3 (E3): "Geralmente, quando estou na BR, posto de gasolina, porque dentro de cidade assim é mais difícil. Também, que nem aqui, tem o mar né? Tem aquelas duchas lá no molhe. A gente se vira. Pra tudo o cara dá um jeito".

Para o E5: "Só quando a gente vai lá na Casa de Apoio, lá no São Vicente. Aqui, se precisar eu tomo banho aqui na torneirinha. Se precisa fazer xixi, cocô, aí tenho que ir lá no banheiro público, quando tá aberto".

Cabe aqui destacar a reflexão realizada por Fraga (2015) acerca da apropriação do espaço das ruas das cidades por pessoas que utilizam esses locais públicos para moradia e manutenção de sua subsistência. Essa discussão investiga de que forma essa estratégia de sobrevivência influencia nas condições de saúde da PSR, uma vez que, a proposição de se pesquisar 
sobre o acesso à saúde de uma determinada população, implica conhecer suas condições de vida. Assim, torna-se necessário problematizar sobre o real significado de "estar em situação de rua" no âmbito das condições de saúde dessa população. Na medida em que entendemos que "estar em situação de rua" implica estar exposto à rua e aos seus movimentos de todas as ordens, podemos começar a compreender melhor esse recorte populacional. O ambiente influencia diretamente na saúde, em seu amplo sentido. Não apenas a moradia ou sua ausência, mas todo o conjunto de relações sociais que perpassa a vida de uma pessoa e que envolve uma série de elementos objetivos e subjetivos. Ou seja, implica, o desenvolvimento de relações de amizade, amor, conflito e todas as dimensões dos sentimentos humanos. Estar na rua influencia também em ações humanas cotidianas, como as necessidades fisiológicas, de higiene, de alimentação, de trabalho, enfim, de uma série de atividades, as quais, muitas delas, remetem a dimensão do que se convencionou atribuir ao espaço privado, íntimo. A realização de atividades corriqueiras como tais desagrada a sociedade, que se choca ao ver o íntimo coexistindo no espaço público.

A fim de suprir suas necessidades básicas as pessoas que vivem nas ruas utilizam-se das mais variadas estratégias, contam com a rede de serviços assistenciais ou com a solidariedade da população. Definem-se como necessidades básicas a alimentação, a higiene e as necessidades fisiológicas, o vestuário e o abrigo. Nessa perspectiva, na maior parte das grandes cidades brasileiras, a rede de serviços de Assistência Social costuma ofertar alternativas para o atendimento a tais necessidades. A oferta, no entanto, muitas vezes não as supre, seja pela insuficiência ou pela baixa qualidade dos serviços prestados. Ao falar-se de qualidade, deve-se levar em conta que faz parte do histórico da política assistencial no País a disponibilização de "serviços pobres para pessoas pobres". Tal tradição tem origem na crença, ainda presente e culturalmente aceita, de que se trata de benevolência, de um favor prestado à população, e não de direitos sociais a serem garantidos. Na maior parte dos casos, os recursos disponíveis para a higiene pessoal dessa população são precários e impróprios, podendo ocasionar sérios problemas de saúde, constrangimentos morais, violência sexual, sujeira no espaço urbano, dentre outros danos (COSTA, 2005; CUNHA; RODRIGUES, 2010).

A solidariedade também contribui para alguma garantia de realização das necessidades básicas. São muitos os exemplos de pessoas, famílias, ou mesmo trabalhadores de estabelecimentos prestadores de serviços, que acabam por "adotar" pessoas que vivem nas ruas nas proximidades de suas residências ou locais de trabalho, garantindoIhes local para dormir, sobras de comida e disponibilidade de água (COSTA, 2005).

Assim, a PSR utiliza-se da mendicância como fonte de recurso para suprir a alimentação, dos locais públicos com água, para banho e lavagem de roupas, dos banheiros públicos, quando existem, e de outros meios, de acordo com o que está disponível a cada momento e em cada realidade urbana (COSTA, 2005).

O E4 também falou sobre como funciona o serviço oferecido pela equipe de abordagem social: "Passa pra ir látomarcafé, tomar um banho, trocar de roupa lá no Centro Pop. Já fui umas três vezes. Agora não costumo ir mais. É muito longe pra poder vir de lá pra cá de pé, né? Só levam, mas pra voltar a pé é muito longe. As coisas eles levam, mas daí como vir com um peso deste?"

É importante destacar, diante dessa fala, como os serviços de assistência social são deslocados geograficamente do local escolhido pela PSR, dificultando então a sua utilização.

De qualquer forma, independente da barreira que torne inviável a utilização dos serviços, as pessoas que vivem nas ruas não costumam utilizá-los com regularidade, 
buscando outras alternativas para satisfazer suas necessidades. Não raramente, os serviços de albergue deixam de ser frequentados por parcela dessas pessoas diante das regras neles estabelecidas, em função da necessidade de organização e convivência. Sob esse ponto de vista, são muito heterogêneas as experiências existentes no país, que vão desde locais onde as regras são construídas com a participação dos usuários e dizem respeito a questões básicas, como não fazer uso de álcool e drogas no local, não portar arma e tomar banho; até experiências de instituições bastante rígidas e seletivas, que têm como objetivo implícito a mudança de comportamentos (COSTA, 2005).

Em relação ao local onde dormem e por vezes acabam por fixar moradia, todos os entrevistados afirmaram dormir nas marquises de estabelecimentos comerciais.

Durmo aqui. Tô dois anos e meio aqui na loja, o gerente me adora. [...] Meu lugar é ali ó. Ali é meu lugar. Ali é o meu local. Ali é a minha casa [...] ó, me procura na loja, qualquer coisa eu tô na loja, meu lugar é na loja. Se eu não tô, é porque fui no banheiro, alguma coisa, tô por ali [...] Ter que dormir no papelão. E vai arrumar papelão aonde? Dia de chuva, tá com frio, tem que dormir no bruto (E4).

Importante ressaltar o sentimento de "propriedade" do lugar onde mora: "Ah, onde for um lugar bom, que não molha, né? Em qualquer lugar. Pra mim é aqui na pracinha, embaixo da marquise" (E5).

Quando não acessam a rede assistencial, as pessoas em situação de rua dormem em "mocós", em baixo de marquises, próximas a órgãos públicos, em rodoviárias ou estações de trem, montam barracas em praças ou áreas verdes, abrigam-se embaixo de pontes. Em geral repousam em grupos, em razão dos riscos que enfrentam pela violência de que são frequentemente alvos (COSTA, 2005). Então, para pensar-se no desenvolvimento de políticas públicas voltadas ao direito de moradia, há que se garantir ofertas habitacionais diferenciadas, entendendo as pessoas em situação de rua como parte de seu público, propondo alternativas de moradia adequadas a sua realidade (COSTA, 2005).

Sobre o trabalho e renda, o E1 referiu: "Responsabilidade mesmo, pra falar a verdade, só tinha em trabalho [...] Então pra gente correr atrás de uma família de volta a gente tem que ter emprego, tem que ter caráter, tem que tá bem, né cara" (E1). E continua:

Daí agora eu tenho que... tipo, hoje, se der um tempinho eu vou tomar um banho no rio aí e vou ter que ir lá pra ver se eu consigo ver se clareou alguma coisa da passagem, né? E dia 23 eu vou ter que ir lá de novo também pra ver se eu consigo transferir meu Bolsa Família pra cá, né cara? Pra eu poder ter uma ajuda. Ou a passagem, ou o Bolsa Família, ou um dos dois tem que entrar pra mim fazer alguma coisa da minha vida, né? Senão, não adianta. É um benefício que me ajuda, né, cara? Não sei quanto que tá agora. Lá eu recebia 84. Tá desde fevereiro cortado esse benefício meu (E1).

\section{O E4 relatou:}

Eu sou pintor. Faço meu servicinho, meu biscatizinho, de vez em quando. Dois, três dias, uma semana [...] Porque eu, não tem dinheiro pra trabalhar não. Eu não tem dinheiro. Tendo uma cervejinha e uma carninha no final de semana, eu trabalho o dia todo. Não tem dia. [...] Aí nós pintemo. Fizemo um pouco no sábado, no domingo. No outro sábado e domingo nós terminemo. A casa por fora e por dentro eu faço em 20 dia. Com ajudante, pra lixar, pra preparar pra mim, tudo, eu faço. Mas com tempo bom, não pode tá úmido, daí é ruim né?

O E5 mantinha expectativa em conseguir o benefício assistencial: "Eu preciso fazer meus documentos porque diz ela que pode fazer pra nós um cartão do Bolsa Família como morador 
de rua. Se fazer, um pra mim e um pra ele, tem como nós pagar, ajuntar pra pagar um aluguelzinho, sabe? Porque, aí sim. Mas se a gente não fazer, não tem".

Com a organização atual do mundo do trabalho, poucas alternativas produtivas restam para a população que sobrevive das ruas. Ainda assim, embora empregos formais e até mesmo subempregos não sejam a realidade da maioria, observa-se que a rua ainda é a alternativa de busca de sobrevivência para uma parcela significativa da população. Em muitos casos, faz parte do processo de ida para a rua a busca, às vezes desesperada, de alternativas de sustento pessoal ou familiar (COSTA, 2005).

As pessoas nessa condição geralmente informam que têm uma profissão, mesmo que já não a estejam exercendo há vários anos. Conforme Castel (1997), o trabalho confere identidade social às pessoas. Nessa perspectiva, dizer que tem uma profissão pode ser uma manifestação de resistência à condição de inutilidade ou de negativa em relação aos preconceitos a que estão sujeitas. Assim, sobrevivem em uma perspectiva diária, sem qualquer condição de planejamento financeiro a médio ou longo prazo, em oposição ao que acontece no caso dos trabalhadores formais.

O peso da determinação social exercida pelotrabalhofica evidentequandosenotaqueem todas as oportunidades em que são abordadas, em pesquisas ou em situação de atendimento, as pessoas em situação de rua revelam que sua principal demanda em relação ao poder público é a questão da geração de alternativas de ocupação e renda. Em parte, isso ocorre como uma resposta ao que socialmente é esperado; em outra medida, reflete o desejo real das pessoas. Esse desejo, em muitos casos concretos não tem condição de tornar-se realidade, diante da fragilidade da condição pessoal decorrente da situação de rua. Cumprir horários, não usar álcool e drogas, apresentar-se adequadamente, readquirir a condição de planejamento de despesas dentro de um mês, são desafios que habitualmente não estão ao alcance de quem já está na rua há algum tempo (COSTA, 2005).

É possível identificar situações diferentes em relação à permanência na rua: ficar na rua - circunstancialmente; estar na rua recentemente; ser da rua - permanentemente. O tempo vivido como moradores de rua é um elemento agravante nesse processo: quanto maiores os lapsos de tempo que permanecem nas ruas, maiores as probabilidades de se tornarem permanentes como seres da rua (ROSA; CAVICCHIOLI; BRETAS, 2005).

Essa maneira de levar a vida provoca uma ruptura com as formas socialmente aceitas de sobrevivência, segundo o princípio legitimador do mercado, no qual o trabalho é provedor da moradia, alimentação e demais necessidades. Viver na rua é romper com o mercado e seu estilo de vida, o que não significa a eliminação total do trabalho ou o impedimento à subsistência, mas o desenvolvimento de novos códigos, de formas específicas de garantia da sobrevivência (AGUIAR; IRIART, 2012).

Ainda em relação ao trabalho e renda, o E3 afirmou:

Olha, é o que você bota no carrinho, né? Porque se você ganha alumínio, você ganha cobre, você ganha metal, a renda é maior, né? Agora, o papelão é centavos, né? Não dá pra ter uma média completa, mas dá pra tirar um dinheirinho, pra não precisar ficar pedindo as coisas pros outros. Às vezes, quando a gente se obriga, um alimento, a gente pede. Mas geralmente, dá pra tirar um dinheirinho por dia. É só ter força de vontade, correr atrás, trabalhar [...] Eu quero ver se eu faço o Bolsa Família, que daí já é uma ajuda, né? Porque todo mundo recebe, por que que eu não posso receber também?

Recolher objetos e materiais pós-consumo, descartados por outras pessoas, constitui-se hoje numa atividade preponderante entre populações em situação de rua. Trata-se de um sistema, 
no qual o descarte da sociedade afluente se torna a matéria prima dos despossuídos. Ainda assim, as atividades relacionadas à reciclagem vêm contribuindo para a redução da pobreza e apresentam impactos sociais e ambientais significativos, articulando dois grandes desafios: redução da pobreza e preservação do meio ambiente (CUNHA; RODRIGUES, 2010).

Alguns expressaram preocupação com a segurança: "Então aqui pra mim teve uma segurança, que aqui é um lugar tranquilo, né, cara. Dá pra você ficar na paz, tal, com a sociedade, tranquilo" (E1). "Já, muitas vezes. É diferente. Tu não confia muito em ninguém, né? Eu tô com ele, eu confio, né? Mas sozinha, a gente fica meio com medo [...] Quando ele não tá, a gente tá sempre perto das pessoas que a gente conhece. Com pessoas que eu nunca vi, eu não tenho coragem de dormir. Vai saber, né?" (E5).

Algumas vezes, acordar para garantir as necessidades fisiológicas é o único objetivo: "Meu plano é ir tomar banho e comer. Eéassim, aí a gente para um pouco né? Só quando começa a abstinência de novo, aí eu vou, vou lá efumo" (E5).

Viver nas ruas quase sempre significa estar em perigo. Os perigos de um espaço instável como a rua se transformam em medo cotidiano de ter os pertences roubados, de ser agredido entre os iguais da rua em alguma briga por espaço ou em uma desavença, de ser vítima de violência sexual, de ser alvo de agressões inesperadas vindas de setores preconceituosos da sociedade ou mesmo dos órgãos oficiais responsáveis pela segurança. A rua é vivida como um mundo à parte da sociedade formal, onde a presença do Estado como garantidor da ordem e da segurança é relativa. Dificultando ainda mais a complexa situação, geralmente as políticas de segurança pública dirigidas a esse público não são voltadas para a sua proteção, mas sim para a criminalização de seus comportamentos e para a "tolerância zero" em relação aos seus atos de transgressão. Tal forma de atuação dos órgãos de segurança reflete o pensamento socialmente predominante, o qual está longe de assegurar a essa população a condição de detentora e digna de direitos humanos que devam ser respeitados (COSTA, 2005). Sob outro enfoque, são escassos exemplos de agregação da população que vive nas ruas por intermédio de alternativas coletivas de segurança. A ocupação do Movimento dos Trabalhadores Sem Teto (MTST) em São Bernardo do Campo/SP, que ocorreu em 2017 e simbolizou uma experiência de organização social e solidariedade, integra um desses raros exemplos. Habitualmente as pessoas em situação de rua dormem em grupos e, às vezes, estabelecem comunidades temporárias de convivência, as quais garantem, em alguma medida, uma proteção mútua. Portanto, sobreviver na rua é uma luta individual e cotidiana, em que cada dia é mais um dia, em que a garantia da própria vida é lucro em relação ao que se pode esperar do cotidiano. Ainda assim, viver nessa condição é tido como alternativa real e possível na perspectiva de quem vive tal realidade. Sobreviver à violência é apenas mais um componente da luta pela manutenção da vida (COSTA, 2005).

Percebe-se que a PSR no município em questão apresenta sérias dificuldades para o atendimento das necessidades humanas básicas, e isto é naturalizado como algo inerente a quem está na rua e desconhece seus direitos ou os tem negado pelas gestões públicas. Gestões essas que, despreparadas para lidar com essa população, acabam por criar políticas públicas higienistas, que tornam a PSR ainda mais marginalizada e invisível. Isso é constatado ao se promoverem campanhas contra a prática de dar esmolas, ao instalar banheiros públicos em apenas alguns pontos da cidade, ao deslocar o Centro Pop (serviço ordenador do cuidado à PSR) e a casa de apoio para bairros das periferias, distantes de onde as pessoas costumam se fixar, ao colocar a dependência química como única situação a ser enfrentada e 
ao apontar como solução serviços segregadores, manicomiais e disciplinadores, que mais exterminam a existência dessas pessoas de que contribuem para a construção de estruturas de apoio social e de promoção de bem estar social.

Muitas vezes, a solidariedade de alguns é o que definirá se a pessoa em situação de rua terá condições de fazer ao menos uma refeição naquele dia. É espantoso saber que nenhum dos entrevistados recebe ao menos o benefício do Bolsa Família ao qual teriam direito, o que com certeza ajudaria a preencher alguma lacuna em sua peregrinação por sobrevivência. Destacase nas falas a forma como são organizados e prestados o atendimento pela rede de assistência social, impondo algumas barreiras de acesso qualificado para boa parte dos usuários. Comumente as pessoas em situação de rua interiorizam o sentimento de não pertencer a este mundo, definindo-se como um objeto, um ser estranho, muito evidente nas falas onde o entrevistado se coloca como se não fizesse parte da sociedade. E assim continuará, enquanto a capacidade de gerar renda e pagar impostos definir o status de cidadão.

Por fim, é importante destacar a ambivalência ou contradição dos sentimentos da PSR. A rua é entendida como sua casa: pela proximidade dos serviços, da comida, do acesso aos caridosos e das marquises públicas e protetoras. E por outro lado, ressentem-se do frio, da chuva, da doença, da renda e tem medo da violência preconceituosa. Os serviços assistenciais deslocados geograficamente de onde habitam os tornam indisponíveis. "Nenhuma pedagogia realmente libertadora pode ficar distante dos oprimidos" (FREIRE, 2014, p. 56).

\section{Considerações finais}

O recorte utilizado para este artigo restringiu aspectos das histórias de vida de pessoas em situação de rua para sua vinculação à categoria analisada.

A formação predominantemente biomédica com uma lógica instrumental não compreende a importância da realidade vista e compartilhada, impossibilitando uma proposta de educação popular em saúde. O que se consegue observar é a PSR como objeto, como demandante, como segregado e não como sujeito, portanto, as propostas dos serviços de saúde ou de assistência social costumam ser verticais e não alteram a essência das relações, perpetuando a marginalização.

A pesquisa permitiu perceber que as histórias de vida das pessoas em situação de rua, no município em questão, são marcadas por uma sucessão de tragédias, perdas, violências, exclusão social, dificuldade de acesso aos serviços públicos e negação aos direitos humanos e, paradoxalmente, algum sentimento de pertencimento, de identidade com grupo, de facilidades para sobrevivência.

É possível constatar, nas falas dos usuários, que os mesmos não se apropriam dos direitos garantidos pela Política Nacional para a PSR, pois enxergam o direito que deve ser garantido pelo Estado como algo de ordem filantrópica. Então, é essencial que essas pessoas sejam apresentadas não apenas à situação em que estão, mas que se possa fortalecer a consciência dessa situação, a fim de garantir o protagonismo em seu processo de construção e transformação.

Consideramos que o Centro Pop pode ser um espaço privilegiado para o desenvolvimento de atividades que promovam a autonomia dos usuários, já que o serviço tem o papel de estimular o desenvolvimento da participação social, o empoderamento e um olhar crítico sobre os seus direitos, fomentando recursos para luta por interesses comuns. Essa é a forma de garantir cidadania à PSR enquanto sujeitos de direitos, bem como sua inserção em movimentos sociais, a fim de promover o pensamento crítico 
acerca da sua realidade e tentar criar formas de superação através de novos projetos de vida.

É desejável e fundamental que mais pesquisas com este tema sejam desenvolvidas, no intuito de permitir a vocalização desta parcela excluída da população. Esta vocalização aparece em outras categorias desta pesquisa e pretende-se analisá-las em novos artigos.

\section{Referências}

AGUIAR M. M.; IRIART J. A. B. Significados e práticas de saúde e doença entre a população em situação de rua em Salvador, Bahia, Brasil. Cad. Saúde Pública, Rio de Janeiro, v. 28, n. 1, p. 115124, jan. 2012. doi: http://dx.doi.org/10.1590/S0102-311X2012000100012.

ALBUQUERQUE, E. M. Avaliação da técnica de amostragem "Respondent-driven Sampling" na estimação de prevalências de Doenças Transmissíveis em populações organizadas em redes complexas. 2009. 99 f. Dissertação (Mestrado em Saúde Pública) - Escola Nacional de Saúde Pública Sérgio Arouca, Rio de Janeiro, 2009.

ARAÚJO, P. et al. O método das histórias de vida na investigação qualitativa em psicologia. Atas CIAIQ. V. 2, 2016. Disponível em: <https://proceedings. ciaiq.org/index.php/ciaiq2016/article/ viewFile/798/784 > . Acesso em: 23 jan. 2018.

BARATA, R. B. et al. Desigualdade social em saúde na população em situação de rua na cidade de São Paulo. Saude Soc. [online], São Paulo, v. 24, suppl. 1, p. 219-232, 2015. doi: http://dx.doi. org/10.1590/S0104-12902015S01019.

BARDIN, L. Análise de Conteúdo. São Paulo: Edições 70, 2011. 225 p.

BRASIL. Decreto Presidencial no 7.053, de 23 de dezembro de 2009. Institui a Política Nacional para a População em Situação de Rua e seu Comitê Intersetorial de Acompanhamento e Monitoramento, e dá outras providências. Disponível em: < http://www.planalto.gov.br/ ccivil_03/_ ato2007-2010/2009/decreto/d7053.htm > . Acesso em: 15 fev. 2018.

. Ministério da Saúde. Manual sobre o cuidado à saúde junto à população em situação

de rua. Brasília: Ministério da Saúde, 2012. Disponível em: <http://dab.saude.gov.br/portaldab/ biblioteca.php?conteudo=publicacoes/manual_saude_populacao_rua > . Acesso em: 23 fev. 2018.

Ministério do Desenvolvimento Social e Combate à Fome. Pesquisa Nacional Sobre a

População em Situação de Rua. Brasília: MDS, 2008. Disponível em: <http:// www.mds.gov.br/ backup/arquivos/sumario_executivo_pop_rua.pdf>. Acesso em: 25 jan. 2018.

CARNEIRO JUNIOR, N. et al. Serviços de saúde e população de rua: contribuição para um debate. Saude Soc. [online], São Paulo, v. 7, n. 2, p. 47-62, 1998. doi: http://dx.doi.org/10.1590/S010412901998000200005.

CARNEIRO JUNIOR, N.; JESUS, C. H.; CREVELIM, M. A. A estratégia saúde da família para a equidade de acesso dirigida à população em situação de rua em grandes centros urbanos. Saude soc. [online] São Paulo, v. 19, n. 3, p. 709-716, 2010. doi: http://dx.doi.org/10.1590/S010412902010000300021. 
CASTEL, R. A dinâmica dos processos de marginalização: da vulnerabilidade à desfiliação. Caderno CRH, Salvador, n. 26/27, p. 19-40, jan./dez. 1997. Disponível em: <https://portalseer.ufba.br/ index.php/crh/article/view/18664 >. Acesso em: 7 fev. 2018.

COSTA, A. P. M. População em situação de rua: contextualização e caracterização. Revista Textos \& Contextos. Porto Alegre, n. 4, ano IV, dez. 2005. Disponível em: < http://revistaseletronicas. pucrs.br/fass/ojs/index.php/fass/article/view/993/773>. Acesso em: 7 fev. 2018.

CUNHA, J. V. Q.; RODRIGUES, M. (Org.). Rua: aprendendo a contar: pesquisa nacional sobre a população em situação de rua. Brasília: Ministério do Desenvolvimento Social e Combate à Fome, 2010. Disponível em: <http://www.mds.gov.br/webarquivos/publicacao/assistencia_social/Livros/ Rua_aprendendo_a_contar.pdf>. Acesso em: 18 fev. 2018.

FONTANELLA, B. J. B. et al. Amostragem em pesquisas qualitativas: proposta de procedimentos para constatar saturação teórica. Cad. Saúde Pública, Rio de Janeiro, v. 27, n. 2, p. 389-394, fev. 2011. doi: http://dx.doi.org/10.1590/S0102-311X2011000200020.

FRAGA, P. População em situação de rua e acesso à saúde. 2015. 192 f. Dissertação (Mestrado em Serviço Social) - Universidade Federal de Santa Catarina, Florianópolis, 2015.

FREIRE, P. Pedagogia do oprimido. 58-ed. Rio de Janeiro: Paz \& Terra, 2014. 256 p.

GERHARDT, T. E. Itinerários terapêuticos em situações de pobreza: diversidade e pluralidade. Cad. Saúde Pública, Rio de Janeiro, v. 22, n. 11, p. 2449-2463, nov. 2006. doi: http://dx.doi. org/10.1590/S0102-311X2006001100019.

MINAYO, M. C. S. O desafio do conhecimento: pesquisa qualitativa em saúde. 14. ed. São Paulo: Hucitec, 2014. 408 p.

PAIVA, I. K. S. et al. Direito à saúde da população em situação de rua: reflexões sobre a problemática. Ciênc. saúde coletiva, Rio de Janeiro, v. 21, n. 8, p. 2595-2606, ago. 2016. doi: http://dx.doi. org/10.1590/1413-81232015218.06892015.

ROSA, A. S.; CAVICCHIOLI, M. G. S.; BRETAS, A. C. P. O processo saúde-doença-cuidado e a população em situação de rua. Rev. Latino-Am. Enfermagem, Ribeirão Preto, v. 13, n. 4, p. 576582, ago. 2005. doi: http://dx.doi.org/10.1590/S0104-11692005000400017.

Submetido em 12 de agosto de 2018.

Aprovado em 23 de novembro de 2018. 